\title{
CORRIGENDUM
}

\section{BAT2 and BAT3 polymorphisms as novel genetic risk factors for rejection after HLA-related SCT}

IS Piras, A Angius, M Andreani, M Testi, G Lucarelli, M Floris, S Marktel, F Ciceri, G La Nasa, K Fleischhauer, MG Roncarolo, A Bulfone, S Gregori and R Bacchetta

Bone Marrow Transplantation (2014) 49, 1452; doi:10.1038/bmt.2014.241

Correction to: Bone Marrow Transplantation (2014) 49, 1400-1404; doi:10.1038/bmt.2014.177; published online 11 August 2014

Since the publication of this article the authors have noticed an error in the list of authors names. GL Nasa should be G La Nasa.
This has now been rectified and the corrected article together with this corrigendum appears in this issue.

The authors would like to apologize for any inconvenience caused. 